\title{
“O PLENO DESENVOLVIMENTO DA PESSOA" E SUA ADESÃO À EDUCAÇÃO SUPERIOR
}

\author{
“EL PLENO DESARROLLO DE LA PERSONA" Y SU ADHESIÓN A LA EDUCACIÓN \\ SUPERIOR
}
“THE FULL DEVELOPMENT OF THE PERSON” AND HIS ADHERENCE IN HIGHER EDUCATION

\author{
Marcelo Haponiuk ROCHA ${ }^{1}$ \\ Alboni Marisa Dudeque PIANOVSKI VIEIRA ${ }^{2}$
}

RESUMO: O estudo tem como objetivo destacar as incorporações do termo Educação como matéria constitucional, sua presença em Constituições anteriores, as razões que levaram à inclusão do termo "Pleno Desenvolvimento da Pessoa" e sua adesão ou não à Educação Superior. A metodologia seguida foi o raciocínio dedutivo, amparado em pesquisa bibliográfica e normas legais relacionadas ao termo pesquisado. A investigação tem como características ser multi/inter/transdisciplinar, agregadora e aglutinadora, das áreas dos conhecimentos usadas como chaves. Como resultado, verifica-se que ajustar padrões culturais e econômicos replicados por sucessivas gerações faz-se necessário à obtenção de um equilíbrio entre desenvolvimento econômico e social e ao desenvolvimento do ser humano.

PALAVRAS-CHAVE: Educação. Pleno desenvolvimento da pessoa. Constituição Federal.

RESUMEN: El objetivo del estudio es resaltar las incorporaciones del término educación como un asunto constitucional, su presencia en las constituciones anteriores, las razones que llevaron a la inclusión del término "pleno desarrollo de la persona" y su adhesión o no en la educación superior. La metodología seguida fue el razonamiento deductivo respaldado por la investigación bibliográfica y las normas legales relacionadas con el término buscado. La investigación tiene como características ser multi/inter/transdisciplinaria, agregando y aglutinando, las áreas de conocimiento utilizadas como claves. El resultado demuestra que es necesario ajustar los patrones culturales y económicos replicados por generaciones sucesivas para lograr un equilibrio entre el desarrollo económico y social y el desarrollo de los seres humanos.

PALABRAS CLAVE: Educación. Desarrollo completo de la persona. Constituición Federal.

\footnotetext{
${ }^{1}$ Pontifícia Universidade Católica do Paraná (PUCPR), Curitiba - PR - Brasil. Doutorando no Programa de PósGraduação em Educação. Membro da Comissão dos Direitos da Pessoa com Deficiência (OAB/Pr). Membro do Conselho Científico da Sociedade Brasileira de Bioética Regional Paraná. Pesquisador do Grupo de Pesquisa Bioética e Biotecnologia PUCPR/CNPq. ORCID: https://orcid.org/0000-0002-1368-2691. E-mail: marcelohaponiukrocha@hotmail.com

${ }^{2}$ Pontifícia Universidade Católica do Paraná (PUCPR), Curitiba - PR - Brasil. Professora do curso de Pedagogia e do Programa de Pós-Graduação em Educação (Mestrado e Doutorado). Doutorado em Educação (PUCPR). ORCID: http://orcid.org/0000-0003-3759-0377. E-mail: alboni@alboni.com
} 
ABSTRACT: It is proposed to understand the meaning of Education as a constitutional matter, its presence in previous Constitutions, the reasons that led to the inclusion of the term "Full Development of the Person", and its effectiveness in Higher Education. The methodology followed was the deductive reasoning supported by bibliographical research and legal norms related to the term researched. The research has as characteristics to be multi / inter / transdisciplinary, aggregator and agglutinative, of the areas of knowledge used as keys. Adjusting cultural and economic patterns replicated by successive generations is necessary to achieve a balance between economic and social development and the development of the human being.

KEYWORDS: Education. Full development of the person. Federal Constitution.

\section{Introdução}

“Quais são os objetivos da Educação no Brasil?”, questiona-se, no plural, deduzindo-se a existência de vários objetivos. Se tal indagação/reflexão fosse posta aos operadores do Direito (advogados, magistrados ou membros do Ministério Público), a imensa maioria das respostas/reflexões, sem receio de errar, conteria menção ao artigo 205 (BRASIL, 1988) da Constituição da República Federativa do Brasil (C.R.F.B.), por razões não muito complexas. A Constituição de um Estado deve ter, como uma das principais razões (de existência e validade), expressar valores, direitos e obrigações buscados pela sua Sociedade e, por consequência, orientar, fomentar, estimular, determinar e delimitar (entre outras tantas funções) sua execução e efetivação e, isso tudo, parece bem absorvido aos operadores do Direito. Intui-se que não basta somente a visão/interpretação/reflexão jurídica ou, no mesmo sentido, a educacional, a filosófica, a antropológica, a sociológica ou a visão política e, sim, todas essas e tantas outras quanto forem pertinentes, de forma conjunta, integrativa e sem fronteiras ou barreiras disciplinares. Assim, uma norma, especialmente as constitucionais, não deveria ser interpretada somente por sua origem ou natureza jurídica-política, mas deveria ser reconhecida como o produto de uma sociedade complexa, heterogênea e multidimensional, sendo as chaves para sua compreensão e efetivação encontradas nas várias áreas do saber humano.

O artigo 205 da C.R.F.B. (BRASIL, 1988) explicita - não se restringindo somente a eles - os objetivos que devem, a princípio, orientar o Sistema de Educação pátrio que, em essência, são três e voltados à pessoa: seu pleno desenvolvimento, seu preparo para o exercício da cidadania e sua qualificação para o trabalho. Dirigindo-se a abordagem à Educação Superior, tem-se dois instrumentos básicos que constituem as primeiras ferramentas para efetivação dos objetivos constitucionais da Educação. A Lei n. ${ }^{0}$ 13.005, de 25 de junho de 2014, aprovou o Plano Nacional de Educação 2014-2024 (BRASIL, 2014) e a Lei n. ${ }^{\circ}$ 9.394/96 (BRASIL, 1996), 
chamada de "Lei de Diretrizes e Bases da Educação Nacional", pontos de referência na nossa investigação quanto à adesão ao objetivo constitucional da Educação ora em estudo. À primeira vista, observa-se, partindo de uma brevíssima análise, a prevalência do último objetivo mencionado (trabalho), a crescente inclusão do segundo (cidadania) e o aparente esquecimento/desconhecimento do "pleno desenvolvimento da pessoa".

Aflora-se, então, o tema de estudo proposto: investigar em que medida o "Pleno desenvolvimento da pessoa" é replicado ou não nas duas normas infraconstitucionais referidas, para que em estudos futuros possa-se aprofundar na busca das causas, razões ou mesmo inviabilidade do objetivo.

Divide-se o presente trabalho em duas seções, além da introdução e das considerações do artigo. Na primeira seção, aborda-se o sentido e o alcance das normas constitucionais para, em seguida, indicar-se a inclusão do termo Educação nos textos das Constituições que vigeram, procedendo-se a uma breve comparação com a norma específica posta na Constituição vigente. A segunda seção volta-se ao entendimento dos sentidos e das razões que poderiam justificar a inclusão do termo "Pleno desenvolvimento da pessoa" como objetivo educacional e investigase nos textos da Lei n. ${ }^{\circ}$ 13.005/2014 e da Lei n. ${ }^{\circ}$ 9.394/96 se eles contemplam e replicam o "Pleno desenvolvimento da pessoa" como objetivo educacional na Educação Superior.

Admite-se que a inclusão do termo "Pleno desenvolvimento da Pessoa" como um dos objetivos educacionais, na C.R.F.B., por si, já deveria ser razão suficiente para reconhecer sua importância e também a decorrente obrigação da sociedade em efetivá-lo. Ainda que desnecessária qualquer outra regulamentação, as repetições nas demais normas, que tratam do conteúdo básico na Educação Superior, teriam como efeito reforçar o valor do objetivo e disseminar sua adesão, dando condições de efetivação e concretização como norteador de conteúdos educacionais.

E como viabilizar a busca do "auto/pleno desenvolvimento" do indivíduo por intermédio do Sistema Educacional? Quais conteúdos permitiriam sua participação na sociedade, seu entendimento das Instituições Sociais (públicas e privadas), sua integração e participação efetiva na comunidade humana? Tudo isso, para permitir um ser humano integral (participativo, crítico, solidário, fraterno), envolvido na busca de uma humanidade mais equilibrada, oferecendo alternativas para seu desenvolvimento. 
Acrescente-se que as evoluções tecnológicas aparentemente estão a exigir como principais competências e habilidades direcionadas à capacidade do ser humano de integrar sua humanidade com a "lógica mecânica" das tecnologias. Especula-se que, dentre os vários desafios opostos ao "Sistema Educacional" pátrio, enfrentar a oportunização do desenvolvimento humano mostra-se como urgente em todos os estágios do sistema, inclusive, na Educação Superior.

A metodologia seguida foi o raciocínio dedutivo amparado em pesquisa bibliográfica e normas legais, usando como chaves obras do Direito, Educação, Sociologia, Filosofia e Bioética, relacionando-as ao termo "Pleno desenvolvimento da pessoa", tendo a investigação como características ser multi/inter/transdisciplinar, agregadora e aglutinadora, das áreas dos conhecimentos usadas como chaves.

\section{A educação como tema das constituições}

Alexandre de Moraes (2005, p. 2), ministro do Supremo Tribunal Federal (STF), cita a definição jurídica de Constituição construída por J. J. Canotilho:

Constituição deve ser entendida como a lei fundamental e suprema de um Estado, que contém normas referentes à estruturação do Estado, à formação dos poderes públicos, forma de governo e aquisição do poder de governar, distribuição de competências, direitos, garantias e deveres dos cidadãos.

O respeito, a valorização e a execução dos objetivos constitucionais da Educação deveriam ser refletidos nas ações das pessoas, do Estado, da Sociedade e das Instituições de forma efetiva e eficaz.

\section{Alcance das normas constitucionais}

Sem a intenção de inverter o curso lógico proposto de desenvolvimento do artigo, fazse necessário, de plano, apresentar uma rápida explanação quanto a força, a fundamentação e o respeito que deveriam ser observados em relação aos dispositivos constitucionais e demais normas que possuam equivalência a eles.

Veja-se o artigo 205 da C.R.F.B. (BRASIL, 1988):

[...] a educação, direito de todos e dever do Estado e da família, será promovida e incentivada com a colaboração da sociedade, visando ao pleno desenvolvimento da pessoa, seu preparo para o exercício da cidadania e sua qualificação para o trabalho (grifo nosso). 
Qualquer norma - de natureza legal ou administrativa, pública ou privada - relacionada à Educação deverá sempre, no mínimo, promover o "pleno desenvolvimento da pessoa, seu preparo para o exercício da cidadania e sua qualificação para o trabalho pleno", isto é, tais objetivos norteiam todo o sistema educacional.

Luís Roberto Barroso (2009), também ministro do STF, ao tratar do tema controle de constitucionalidade, destaca duas premissas naturais existentes no texto constitucional: a supremacia e a rigidez. Sustenta Barroso que as normas constitucionais se encontram em posição mais elevada em relação às demais normas legais ou administrativas (ex.: Leis Ordinárias, Leis Complementares, Portarias, Resoluções, Atos Administrativos etc.), as quais, para ter sua validade reconhecida, devem respeitar as disposições constitucionais, caracterizando sua supremacia. A rigidez decorre da forma como a Constituição é construída, “[...] um processo de elaboração diverso e mais complexo do que aquele apto a gerar normas infraconstitucionais" (BARROSO, 2009), dando fundamento para as normas constitucionais nortearem as demais normas legais ou administrativas e delas exigir conformidade com o sentido da Carta Magna.

Pertinente, contudo, compreender que a inclusão do termo "pleno desenvolvimento", em matéria de Educação na Constituição, representa a agregação e o reconhecimento de valores pela sociedade, que surgem de interpretações ou modelos contemporâneos direcionados às relações humanas, nas nações que adotam o regime democrático. Ao comparar-se textos constitucionais anteriores, torna-se possível identificar os valores presentes nos períodos históricos de vigência de cada Constituição, compreendendo-se as influências e os rumos que eram traçados para e/ou pela sociedade.

\section{A educação nas constituições brasileiras}

Voltar o olhar ao passado - para identificar valores presentes nos textos constitucionais anteriores - exige reconhecer as perspectivas que influenciavam o dado no momento histórico analisado. Influenciar-se da visão contemporânea é moldar o passado aos significados do termo ou na sua compreensão atual.

No Brasil, além da C.R.F.B de 1988, vigeram outras seis Constituições (1824, 1891, 1934, 1937, 1946, 1967 e Emenda Constitucional n. ${ }^{\circ}$ 01/69). Fazendo-se uso de busca rápida do termo "Educação" nas disposições constitucionais antecedentes, constata-se que a "Constituição Política do Império do Brasil” (BRASIL, 1824) não faz referência ao termo "Educação". 
O texto original da "Constituição da República dos Estados Unidos do Brasil" (BRASIL, 1891) também não tratou da matéria, que recebeu dimensão constitucional somente com Emenda Constitucional de 1926, no artigo 34, item “30”, que atribuiu competência privativa ao Congresso Nacional para legislar sobre Educação Superior, competência concorrente, também do Congresso Nacional, para criar Instituições de Ensino Superior (art. $\left.35,3 .^{\circ}\right)$.

A primeira Carta Maior a incluir o termo "Educação" foi a "Constituição dos Estados Unidos do Brasil” (BRASIL, 1934), que determinou competência privativa da União para "traçar as diretrizes da educação nacional" (art. 5. , inciso XIV) e também inovou ao conter em seu corpo o "Título V”, denominado "Da Família, da Educação e da Cultura" e, ainda, no artigo 149 ditar os propósitos básicos da Educação. Veja-se:

[...] a educação é direito de todos e deve ser ministrada, pela família e pelos Poderes Públicos, cumprindo a estes proporcioná-la a brasileiros e a estrangeiros domiciliados no País, de modo que possibilite eficientes fatores da vida moral e econômica da Nação, e desenvolva num espírito brasileiro a consciência da solidariedade humana.

Dessa forma, proporcionar a Educação não era visto como dever exclusivo do Estado, e os fins buscados visavam a eficiência "da vida moral e econômica da Nação", além do desenvolvimento "num espírito brasileiro a consciência da solidariedade humana" (BRASIL, 1934).

A “Constituição dos Estados Unidos do Brasil”" (BRASIL, 1937) faz referência ao tema "Educação" sem apresentar claramente seus objetivos.

As “Constituição da República Federativa do Brasil” (BRASIL, 1946, 1964) e a Emenda n. ${ }^{\circ}$ 01/69 (BRASIL, 1969) elencam a "liberdade" e a "solidariedade humana" como princípios inspiradores da Educação em todas elas, sendo que as duas últimas acrescentam o "princípio da unidade nacional".

Diante do explanado, observa-se que a definição clara dos objetivos da Educação, no plano das normas constitucionais, somente ocorreu a partir da promulgação da Constituição da República Federativa do Brasil em 1988, com a vinculação de toda Educação no Brasil às finalidades de promover o "pleno desenvolvimento da pessoa, seu preparo para o exercício da cidadania e sua qualificação para o trabalho pleno" (BRASIL, 1988). Todavia, após pouco mais de três décadas de vigência, constata-se que o "pleno desenvolvimento da pessoa" não aparenta ter tido adequada receptividade nas normas infraconstitucionais. 


\section{"Pleno desenvolvimento da pessoa"?}

\section{Conceito ou elementos orientadores?}

Qual o conceito do termo "Pleno Desenvolvimento da Pessoa"? É razoável fixar-se na busca de um conceito para o termo? É possível incentivar e promover o "Pleno Desenvolvimento da Pessoa" sem que se tenha uma concepção exata do termo?

Com o perdão do mau exemplo - e não fazendo apologia a qualquer crime ambiental visualize uma ave silvestre jovem sendo colocada em cativeiro. Ainda que receba alimentação, cuidados de saúde de forma regular, em espaço amplo e tendo suas necessidades supridas, mesmo com tudo isso, sua existência estaria limitada aos muros ou grades de seu viveiro, aos limites de entendimento e reconhecimento (como necessidades) daqueles que cuidam da ave e que somente seriam atendidas quando o cuidador as reconhecesse.

Elaborar um conceito fechado ao termo "Pleno Desenvolvimento da Pessoa" seria tentar conter a vazão de um direito/valor/garantia de natureza fluída, que se apresenta em incontáveis formas, modifica-se conforme a época e o lugar, ajusta-se com o convívio entre os seres humanos, transitando da perspectiva do indivíduo para a dimensão difusamente coletiva, em contínuo vai e vem.

Opta-se então, aqui, pelo caminho de trabalhar-se com o termo considerando-o aberto e submetido à constante e permanente (re)elaboração, como um direito/valor/garantia em perpétuo diálogo com a realidade.

Não obstante escolher a opção de não buscar conceituação do termo, seria possível balizar a compreensão do objetivo "Pleno Desenvolvimento da Pessoa" via elementos que contribuam à sua compreensão e execução, que são encontráveis em documentos internacionais.

Antes da indicação de alguns elementos balizadores, faz-se necessário destacar que as primeiras percepções atribuídas ao termo em estudo vinculavam desenvolvimento imediatamente ao plano econômico/financeiro e coletivo (Estados, Nações, comunidades).

A Declaração Universal dos Direitos Humanos (DUDH), em seu artigo XXII, traz o termo "livre desenvolvimento da sua personalidade" como um direito humano e, um pouco antes no mesmo artigo, associa a indispensabilidade dos "direitos econômicos (sociais e culturais) ao desenvolvimento" (ONU, 1948).

No mesmo sentido, o artigo primeiro do "Pacto Internacional de Derechos Económicos, Sociales y Culturales", voltado à livre determinação dos povos, associa o termo 
"desenvolvimento" às dimensões econômicas, sociais e culturais de desenvolvimento (ONU, 1966).

Ainda no palco internacional, a mudança de orientação é exposta na "Declaración sobre el derecho al desarrollo”, expressa na Resolução n. ${ }^{\circ}$ 41/128, adotada pela Assembleia Geral em 4 de dezembro de 1986 (ONU, 1986).

Extrai-se, especialmente nos dois primeiros artigos, do texto desta declaração, que o direito ao desenvolvimento é um direito humano inalienável, de amplitude coletiva e individual, sendo o ser humano o destinatário central tanto na condição de detentor, acionador e responsável ativo de tal direito criador, com vinculação direta com o bem estar coletivo e individual.

\section{Como objetivo constitucional da educação}

A tentativa de identificar a razão de inclusão, em dispositivo constitucional, do termo "Pleno Desenvolvimento da Pessoa" como objetivo da Educação deve passar, também, por uma verificação nas Constituições anteriores do Brasil. Conforme já indicado anteriormente, a “Constituição dos Estados Unidos do Brasil”, de 1934, incluiu o tema Educação em seu "Título V", e ditou no artigo 149 propósitos básicos da educação, como possibilitar "fatores da vida moral e econômica da Nação", que estavam vinculados a serem desenvolvidos "num espírito brasileiro a consciência da solidariedade humana". Essencialmente, o ser humano individualmente não era considerado como foco da Educação, sua participação estava vinculada a um interesse coletivo (moral e economia da Nação) e a solidariedade humana dependia das limitações de um espírito brasileiro a ser desenvolvido. Em outras palavras, a régua seletiva estava voltada à "Nação brasileira" (BRASIL,1934).

A expressão "solidariedade humana" novamente é repetida nas "Constituição da República Federativa do Brasil" de 1946, de 1964 e sua Emenda n. ${ }^{\circ}$ 01/69 e, nas duas últimas, agregadas à expressão "liberdade" vinculada à "Nação" e ao "princípio da unidade nacional" (BRASIL, 1964, 1969). O ser humano, considerado na sua individualidade, ainda não era tema constitucional educacional.

Observe-se que a inclusão do tema "Educação", nas Constituições, está diretamente relacionada à forma como as organizações humanas (Estados, grupos, órgãos etc.) consideram seus indivíduos membros. Assim: se o indivíduo é posto em primeiro plano, as organizações incluem também entre seus objetivos o desenvolvimento deles; se o Estado prevalece em relação aos indivíduos, o desenvolvimento destes envolve competências voltadas a fortalecer o Estado (habilidades de trabalho, sentido de nacionalidade, cidadania etc.). 
Em estudo voltado ao entendimento do termo "dignidade humana", Rocha (2016) destaca que os conceitos de compaixão, amor ao próximo, solidariedade, dentre outros, alteraram a perspectiva dominante anterior, que situava, por assim dizer, o ser humano como “objeto" do Estado para identificá-lo como filho de Deus (VALLS, 2013), e sua imagem e semelhança (JORDANA, 2013), fundamentando sua dignidade, já semeando uma visão universalista que, com o passar do tempo, acaba vingando (LEPARGNEUR, 2009).

Marshal, desenvolvendo os aspectos da cidadania, identifica três fases do processo de modificação da relação do Estado com o indivíduo. Na primeira (identificada pelo autor como elemento civil) são afirmados os direitos necessários à liberdade individual (ir e vir, imprensa, pensamento, fé, propriedade, justiça etc.). Já a segunda fase (elemento político) envolve o direito de participar do poder político como membro de um organismo político ou como eleitor dos membros. Por fim, tem-se a assunção do mínimo bem-estar econômico e segurança ao direito de participar na herança social e levar a vida de acordo com os padrões da sociedade (elemento social) (MARSHAL, 1967).

Ao longo da história, na relação entre Estado (Reinos, Cidades, Sociedade, Comunidade etc.) e indivíduo, destacou-se inicialmente que este era um objeto do Estado e o seu desenvolvimento era voltado a suprir as necessidades do Estado (militar, econômica, política, religiosa etc.). Em sequência, são afirmados certos direitos voltados à liberdade e à igualdade entre os seres humanos, gerando algumas limitações nas intervenções que o Estado poderia ter na vida dos indivíduos sem, contudo, alterar significativamente a relação quanto às razões buscadas para incentivar o desenvolvimento do ser humano, continuando a servir para suprir as necessidades da Sociedade. Em continuidade, com a participação dos indivíduos (direito ao voto, por exemplo), o respeito ao indivíduo e, por consequência, o estímulo ao desenvolvimento pessoal passa a ser reconhecido como valor a ser buscado e garantido pelo Estado, que recebe limites e tarefas de proteção/assistência do ser humano (ROCHA, 2016).

Considera-se a possibilidade e necessidade de maior aprofundamento - na busca do sentido e aplicação do objetivo posto no termo "Pleno Desenvolvimento da Pessoa" - baseado na transdisciplinaridade, o que seria mais útil e eficaz, contudo, poder-se-ia causar o distanciamento do objetivo deste artigo, tendo em conta a vastidão de conteúdo e pelos limites acadêmicos do autor.

John Dewey (1978, p. 53), ainda que tratando da educação infantil, indica uma ideia de desenvolvimento, discorrendo sobre o sentido a ser buscado no termo: 
Desenvolvimento não quer dizer retirar qualquer coisa da própria natureza. $\mathrm{O}$ verdadeiro desenvolvimento é um desenvolvimento pela experiência. E isso será impossível, se não providenciarmos um meio educativo que permita $o$ funcionamento dos interesses e forças que forem selecionadas como mais úteis. Esses interesses e essas forças, ou capacidades, devem entrar em operação, o que dependerá essencialmente dos estímulos que os envolvam e do material sobre o qual se exercitem. O problema de direção é, pois, o problema de seleção dos estímulos adequados aos instintos e impulsos que desejamos desenvolver.

Assim, promover e incentivar o "pleno desenvolvimento" do indivíduo, por intermédio do Sistema Educacional, caminharia tanto pelo autoconhecimento quanto pelo estímulo à sua participação na sociedade, ao seu entendimento das Instituições Sociais (públicas e privadas) e à sua integração e participação efetiva na comunidade humana. Tudo isso para permitir um ser humano integral (participativo, crítico, solidário, fraterno), envolvido na busca de uma humanidade mais equilibrada, oferecendo alternativas para o seu desenvolvimento.

\section{No Ensino Superior}

Em 1550, na Bahia, os jesuítas fundaram o primeiro estabelecimento de ensino superior, oferecendo os cursos de Artes e Teologia a partir de 1553. O modelo de ensino superior atual não seguiu o modelo dos jesuítas e, sim, das variadas instituições criadas no início do século XIX, seguindo de cátedras isoladas de ensino superior - Medicina na Bahia e no Rio de Janeiro em 1808, e Engenharia na Academia Militar também no Rio de Janeiro, em 1810. Em 1827, o imperador Pedro I acrescentou em Olinda e em São Paulo os Cursos Jurídicos aos quadros de cursos já existentes. Os estudantes nesse longo período basicamente eram fillhos de funcionários públicos, senhores de engenho, criadores de gados ou mineradores. Essencialmente, os objetivos buscados na Educação visavam o conhecimento necessário ao desempenho das funções profissionais, aumento do prestígio familiar ou como meio de conseguir melhores condições de vida, ocupando cargos de maior remuneração, prestígio e poder (CUNHA, 2015).

A Lei n. ${ }^{\circ}$ 13.005, de 25 de junho de 2014, aprovou o Plano Nacional de Educação 20142024 (BRASIL, 2014), destacando os objetivos da Educação:

\footnotetext{
Art. $2^{\circ}$. São diretrizes do PNE:

I - erradicação do analfabetismo;

II - universalização do atendimento escolar;

III - superação das desigualdades educacionais, com ênfase na promoção da cidadania e na erradicação de todas as formas de discriminação;

IV - melhoria da qualidade da educação;

V - formação para o trabalho e para a cidadania, com ênfase nos valores morais e éticos em que se fundamenta a sociedade;

VI - promoção do princípio da gestão democrática da educação pública;
} 
VII - promoção humanística, científica, cultural e tecnológica do País;

VIII - estabelecimento de meta de aplicação de recursos públicos em educação como proporção do Produto Interno Bruto - PIB, que assegure atendimento às necessidades de expansão, com padrão de qualidade e equidade;

IX - valorização dos(as) profissionais da educação;

$\mathrm{X}$ - promoção dos princípios do respeito aos direitos humanos, à diversidade e à sustentabilidade socioambiental (grifo nosso).

De plano, constata-se inexistir qualquer menção ao objetivo constitucional "Pleno Desenvolvimento da Pessoa", sendo que o item "12.11" apresenta como estratégia voltada ao Ensino superior "fomentar estudos e pesquisas que analisem a necessidade de articulação entre formação, currículo, pesquisa e mundo do trabalho, considerando as necessidades econômicas, sociais e culturais do País" (BRASIL, 2014, grifo nosso).

A Lei n. ${ }^{\circ}$ 9.394/96 - Lei de Diretrizes e Bases da Educação Nacional - em seu artigo $2^{\circ}$, delimita (BRASIL, 1996):

[...] a educação, dever da família e do Estado, inspirada nos princípios de liberdade e nos ideais de solidariedade humana, tem por finalidade o pleno desenvolvimento do educando, seu preparo para o exercício da cidadania e sua qualificação para o trabalho (grifo nosso).

Mais adiante, no mesmo dispositivo legal, no "Capítulo IV", dedicado ao Ensino Superior, nada consta em relação ao "pleno desenvolvimento do educando":

Art. 43. A educação superior tem por finalidade:

I - estimular a criação cultural e o desenvolvimento do espírito científico e do pensamento reflexivo;

II - formar diplomados nas diferentes áreas de conhecimento, aptos para a inserção em setores profissionais e para a participação no desenvolvimento da sociedade brasileira, e colaborar na sua formação contínua;

III - incentivar o trabalho de pesquisa e investigação científica, visando o desenvolvimento da ciência e da tecnologia e da criação e difusão da cultura, e, desse modo, desenvolver o entendimento do homem e do meio em que vive; IV - promover a divulgação de conhecimentos culturais, científicos e técnicos que constituem patrimônio da humanidade e comunicar o saber através do ensino, de publicações ou de outras formas de comunicação;

$\mathrm{V}$ - suscitar o desejo permanente de aperfeiçoamento cultural e profissional e possibilitar a correspondente concretização, integrando os conhecimentos que vão sendo adquiridos numa estrutura intelectual sistematizadora do conhecimento de cada geração;

VI - estimular o conhecimento dos problemas do mundo presente, em particular os nacionais e regionais, prestar serviços especializados à comunidade e estabelecer com esta uma relação de reciprocidade;

VII - promover a extensão, aberta à participação da população, visando à difusão das conquistas e benefícios resultantes da criação cultural e da pesquisa científica e tecnológica geradas na instituição.

VIII - atuar em favor da universalização e do aprimoramento da educação básica, mediante a formação e a capacitação de profissionais, a realização de 
pesquisas pedagógicas e o desenvolvimento de atividades de extensão que aproximem os dois níveis escolares.

Repita-se que a inclusão do termo "Pleno desenvolvimento da Pessoa" como um dos objetivos educacionais na Constituição da República Federativa do Brasil, por si, já deveria ser a razão suficiente para reconhecer sua importância e, também, a obrigação social comum de efetivá-lo. As normas infraconstitucionais, quando replicam o termo, poderiam causar o efeito de disseminar e reforçar o valor do objetivo, sua efetivação e concretização, como norteador de conteúdos educacionais.

\section{Considerações finais}

A prevalência direcionada, nos esforços do Estado, ao também objetivo constitucional da Educação de preparo do ser humano para o trabalho, sob a justificativa de promoção do desenvolvimento econômico e social do País, reforça uma matriz patrimonialista voltada, preferencialmente, ao objeto, aos bens, à produção e pouco ao ser humano. A qualificação para o trabalho foi incluída como objetivo da Educação a partir das primeiras décadas do século passado, como reflexo da mudança de considerável parte da população rural ao meio urbano industrial. Buscando suprir as exigências de várias habilidades que não faziam parte do dia a dia da população rural, desde então continua a repercutir nas mais variadas normas infraconstitucionais.

O preparo para o exercício da cidadania, outro objetivo da Educação, pode-se pensar ser uma consequência, quase que simultânea, da nova configuração da população brasileira se estabelecendo nas cidades, primeiras décadas do século passado, gerando grandes transformações também na dimensão normativa.

No plano nacional, o Brasil estava se firmando como nação na busca de identidade, reconhecimento externo e ajustando-se no seu papel econômico, financeiro, legislativo, político.

Já na seara internacional, dois grandes conflitos mundiais (re)marcaram as divisões entre os países ou grupos destes também nas dimensões econômicas, financeiras, comerciais, ideológicas, política, entre outras. Tudo isso refletindo nas relações entre a população e o Estado.

Não seria absurdo intuir que as reflexões mencionadas nos dois parágrafos anteriores demonstram a maior projeção dos objetivos constitucionais da Educação voltados ao trabalho e à cidadania. 
Vivemos, presenciamos e descobrimos, na atualidade, grandes transformações decorrentes de novas tecnologias - real/virtual, analógico/digital, público/privado, entre outras -, e também por essas razões a inclusão de objetivo com uma raiz direcionada à promoção do desenvolvimento do ser humano apresenta-se como um grande desafio.

Ajustar padrões culturais e econômicos replicados por sucessivas gerações faz-se necessário à obtenção de um equilíbrio entre desenvolvimento econômico/social e o desenvolvimento humano.

Desejou-se estimular a reflexão do termo "Pleno Desenvolvimento da Pessoa" com a potencial possibilidade de estabelecer o estudo conectando diversas áreas do saber para conjugar de forma plural os conhecimentos, tendo-se como metas a efetivação, a promoção e o incentivo do objetivo constitucional da Educação mais desconhecido e ignorado.

O preparo para viver com as evoluções tecnológicas pode requer competências e habilidades direcionadas e relacionadas à capacidade de o ser humano integrar sua humanidade com a "lógica mecânica" das tecnologias, e a educação que objetiva o desenvolvimento do ser humano em equilíbrio com o desenvolvimento econômico e social pode ser a chave a ser atingida.

\section{REFERÊNCIAS}

BARROSO, L. R. O controle de constitucionalidade no direito brasileiro. 4. ed. rev. atual. São Paulo: Saraiva, 2009.

BRASIL. Constituição (1824). Constituição Política do Império do Brasil, Rio de Janeiro,1823. Disponível em:

http://www.planalto.gov.br/ccivil_03/Constituicao/Constituicao24.htm. Acesso em: 18 abr. 2018 .

BRASIL. Constituição (1891). Constituição da República dos Estados Unidos do Brasil. Rio de Janeiro, 1891. Disponível em:

http://www.planalto.gov.br/ccivil_03/Constituicao/Constituicao91.htm. Acesso em: 18 abr. 2018.

BRASIL. Constituição (1934). Constituição da República dos Estados Unidos do Brasil. Rio de Janeiro, 1934. Disponível em: http://www.planalto.gov.br/ccivil_03/Constituicao/Constituicao34.htm. Acesso em: 18 abr. 2018 .

BRASIL. Constituição (1937). Constituição dos Estados Unidos do Brasil. Rio de Janeiro, 1937. Disponível em: http://www.planalto.gov.br/ccivil_03/Constituicao/Constituicao37.htm. Acesso em: 18 abr. 2018. 
BRASIL. Constituição (1946). Constituição dos Estados Unidos do Brasil. Rio de Janeiro, 1946. Disponível em:

http://www.planalto.gov.br/ccivil_03/Constituicao/Constituicao46.htm. Acesso em: 18 abr. 2018.

BRASIL, Constituição (1967). Constituição da República Federativa do Brasil. Brasília, 1964. Disponível em: http://www.planalto.gov.br/ccivil_03/Constituicao/Constituicao67.htm. Acesso em: 18 abr. 2018.

BRASIL. Constituição (1988). Constituição da República Federativa do Brasil. Brasília, 1988. Disponível em: http://www.planalto.gov.br/ccivil_03/Constituicao/Constituicao.htm. Acesso em: 10 ago. 2017.

BRASIL. Emenda Constitucional (1969). Emenda Constitucional n. 1 de 1969. Brasília, 1969. Disponível em: http://www.planalto.gov.br/ccivil_03/Constituicao/Constituicao67.htm. Acesso em: 18 abr. 2018.

BRASIL. Lei n. 9.394, de 20 de dezembro de 1996. Estabelece as diretrizes e bases da educação nacional. Brasília, 1996. Disponível em:

http://www.planalto.gov.br/Ccivil_03/leis/L9394compilado.htm. Acesso em: 18 abr. 2018.

BRASIL. [Plano Nacional de Educação (PNE)]. Plano Nacional de Educação 2014-2024 [recurso eletrônico]: Lei n. ${ }^{\circ} 13.005$, de 25 de junho de 2014, que aprova o Plano Nacional de Educação (PNE) e dá outras providências. Brasília: Câmara dos Deputados, Edições Câmara, 2014. 86 p. (Série legislação; n. 125). "Atualizada em: 1/12/2014".

CUNHA, L. A. Ensino superior e universidade no Brasil. In: LOPES, E. M. T.; FARIA FILHO, L. M.; VEIGA, C. G. (org.). 500 anos de educação no Brasil. 5. ed. Belo Horizonte: Autêntica, 2015. p. 151-204.

DEWEY, J. Vida e educação. Trad. Anísio S. Teixeira. 11. ed. São Paulo: Melhoramentos, 1978.

JORDANA, J. L. V. Dignidade, direitos humanos e bioética. In: CASADO, M. (org.). Sobre a dignidade e os princípios: análise da Declaração Universal sobre Bioética e Direitos Humanos da Unesco. Porto Alegre: EDIPUCRS, 2013. p. 115-127.

LEPARGNEUR, H. A dignidade humana, fundamento da bioética e seu impacto para a eutanásia. In: PESSINI, L.; BARCHIFONTAINE, C. P. (coord.). Fundamentos da bioética. 4. ed. São Paulo: Paulus, 2009. Cap. XII, p. 177-188.

MARSHAL, T. H. Cidadania, classe social e status. Trad. M. D. Gadelha. Rio de Janeiro: Zahar, 1967.

MEIRELLES, J. M. L. (org.). Biodireito em discussão. Curitiba: Juruá, 2011.

MORAES, A. Direito constitucional. 17. ed. São Paulo: Atlas, 2005. 
ONU. Declaração Universal dos Direitos Humanos. 1948. Disponível em:

https://nacoesunidas.org/wp-content/uploads/2018/10/DUDH.pdf. Acesso em: 06 ago. 2020.

ONU. Pacto Internacional de Derechos Económicos, Sociales Y Culturales. Adoptado y abierto a la firma, ratificación y adhesión por la Asamblea General em su resolución $2200 \mathrm{~A}$ (XXI). 16 dez. 1966. Disponível em: https://acnudh.org/load/2014/10/CoreTreatiessp.1729.pdf. Acesso em: 06 ago. 2020.

ONU. Declaracion sobre el derecho al desarrollo. 1986. Disponível em:

https://www.ohchr.org/sp/professionalinterest/pages/righttodevelopment.aspx. Acesso em: 06 ago. 2020.

ROCHA, M. H. A dignidade dos profissionais de saúde a luz da Bioética. $2016.69 \mathrm{f}$. Dissertação (Mestrado) - Pontifícia Universidade Católica do Paraná, Curitiba, 2016.

SECRETARIA DE EDUCAÇÃO SUPERIOR. Livro SESU, Brasília. Disponível em: http://portal.mec.gov.br/sesu/arquivos/pdf/livrosesu.pdf. Acesso em: 10 ago. 2017.

VALLS, R. A dignidade humana. In: CASADO, M. (org.). Sobre a dignidade e os princípios: análise da Declaração Universal sobre Bioética e Direitos Humanos da Unesco. Porto Alegre: EDIPUCRS, 2013. p. 69-78.

\section{Como referenciar este artigo}

ROCHA, M. H.; PIANOVSKI VIEIRA, A. M. D. "O pleno desenvolvimento da pessoa” e sua adesão à educação superior. Revista Ibero-Americana de Estudos em Educação, Araraquara, v. 16 , n. 4 , p. 2443-2457, out./dez. 2021. e-ISSN: 1982-5587. DOI: https://doi.org/10.21723/riaee.v16i4.13434

Submetido em: $23 / 07 / 2021$

Revisões requeridas em: 21/08/2021

Aprovado em: 19/09/2021

Publicado em: 21/10/2021 